\title{
TRIBUNAL CONSTITUCIONAL Y PROCESO SECESIONISTA CATALÁN: RESPUESTAS JURÍDICO-CONSTITUCIONALES A UN CONFLICTO POLÍTICO-CONSTITUCIONAL ${ }^{1}$
}

\author{
JOSEP M. ${ }^{a}$ CASTELLÀ ANDREU \\ Catedrático $(A)$ de Derecho Constitucional \\ Universidad de Barcelona
}

\section{SUMARIO}

I. Introducción. II. Cataluña y el Tribunal Constitucional antes del inicio del proceso secesionista. III. El proceso secesionista ante el Tribunal Constitucional (2012-2016). IV. Las argumentaciones del Tribunal Constitucional en las sentencias sobre el proceso secesionista. V. A modo de conclusión.

\section{INTRODUCCIÓN}

Desde 2012 se ha producido en Cataluña una aceleración secesionista por parte de las instituciones autonómicas y de un segmento relevante de la opinión pública que ha puesto sobre el tapete cuestiones que apenas se habían suscitado ni en los debates constituyentes ni en los años de vigencia del actual sistema democrático y constitucional. La Constitución española, como casi todas las normas fundamentales, no contiene ninguna «cláusula de secesión»—entendida como derecho a la autodeterminación de los territorios que forman España o como procedimiento para poder alcanzarla ${ }^{2}$. En cambio, igual que otras constituciones de

1 Grupo de estudios sobre Democracia y Constitucionalismo (GEDECO. Grupo consolidado por la Generalitat en 2014). El presente trabajo se inserta en el marco del proyecto financiado por el MINECO DER2012-37567 sobre «Democracia multinivel: la participación de los ciudadanos y de los entes territoriales en los procesos de decisión pública».

2 En los debates constituyentes, en la Comisión de asuntos constitucionales del Congreso se rechazó (por 24 votos en contra y uno a favor) la enmienda defendida por el diputado de la izquierda abertzale F. Letamendía al artículo 149 del proyecto de Constitución que preveía un procedimiento para ejercer el derecho a la autodeterminación de los pueblos del Estado (con celebración de referéndum a propuesta de la Asamblea 
Estados compuestos, incluye algunos instrumentos para afrontar situaciones de crisis graves, como las derivadas de demandas secesionistas (particularmente la cláusula de coerción estatal del art. $155 \mathrm{CE}$, pero no solo ella ${ }^{3}$ ).

En las páginas que siguen vamos a abordar varios asuntos jurídico-constitucionales que ha suscitado la escalada secesionista en Cataluña desde la perspectiva de la intervención del Tribunal Constitucional en la misma. Sin duda, una crisis que cuestiona la propia unidad del Estado es una crisis política, es más, es la crisis político-constitucional por excelencia, porque afecta a la integridad y a la continuidad del sujeto político — el pueblo y la nación españoles- que lo fundamenta, y no solo a la forma de organizarlo (forma de estado y forma de gobierno) ni a los concretos problemas de su funcionamiento ordinario. Es una crisis que incide sobre la capacidad de integración política del sistema constitucional e institucional vigente, porque una parte de la comunidad política, localizada en una entidad autónoma, pasa a considerarlo como ajeno y a reclamar la fundación de otra comunidad política. Pero tal naturaleza política de la crisis no ha sido óbice para que el Tribunal Constitucional asumiera frente a la misma un papel activo, lo que ha tenido efectos institucionales que van más allá de la mera resolución en términos estrictamente constitucionales de los casos planteados. El Tribunal ha aparecido ante la opinión pública como el guardián de la Constitución y como el garante de la unidad del Estado, lo que ha provocado reacciones contrapuestas, ya sea de respeto por la función desempeñada ya de minar su legitimidad institucional por parte de los sectores partidarios de la secesión. Y ante este tipo de valoraciones ha pasado a un segundo plano el análisis jurídico de los argumentos empleados en las sentencias.

A lo largo de estos cuatro años se han visto actuaciones de distinto tipo procedentes de las instituciones catalanas, tales como la aprobación de varias resoluciones por parte del Parlamento de Cataluña proclamando el carácter soberano del pueblo catalán y el derecho a decidir del mismo, y anunciando la desobediencia a las instituciones estatales —incluyendo al propio Tribunal Constitucional—, así como la aprobación por dicho Parlamento y por el gobierno catalán de normas y la realización de actuaciones que preveían, entre las más destacadas, la celebración de una consulta popular sobre la secesión. Las instituciones estatales

del territorio, y debiendo obtener el voto favorable de la mayoría absoluta del censo electoral de cada una de las provincias o circunscripciones afectadas). Ver Diario de Sesiones de las Cortes Generales. Congreso de los Diputados, n. ${ }^{\circ}$ 91, 16 de junio de 1978, pp. 3427-3435.

3 Además de los estados excepcionales del artículo $116 \mathrm{CE}$, en particular del Estado de sitio. Es original de la Constitución española la previsión de una serie de instrumentos que, aunque no específicamente diseñados para este tipo de crisis, son garantías de la unidad del Estado y han servido al Gobierno central para abordar la crisis catalana. En concreto, nos referimos a: a) la atribución al Estado de la competencia exclusiva sobre la autorización de referendos del artículo 149.1.32 CE, sin la cual el referéndum autonómico no se puede convocar; y b) la suspensión automática por cinco meses de actos y resoluciones de las Comunidades Autónomas que el Gobierno del Estado impugne ante el Tribunal Constitucional por motivos distintos de los competenciales (art. 161.2 CE) y que la LOTC incorpora al recurso de inconstitucionalidad y al conflicto de competencias. 
— el gobierno y su Presidente particularmente- han trasladado al Tribunal Constitucional la respuesta a tal desafío, impugnando las normas, resoluciones y actuaciones de la Generalitat, lo que provocaba la suspensión automática e inmediata de las mismas. En las páginas siguientes nos centraremos en aquellas impugnaciones que han dado lugar ya a sentencias del Alto Tribunal ${ }^{4}$.

El gobierno del Estado ha optado por rechazar las pretensiones secesionistas con argumentos sobre todo de índole jurídica, basados en la invocación de la Constitución y el Estado de Derecho (en lugar de resaltar los beneficios de la unión), y con primar la judicial sobre otro tipo de respuestas de carácter estrictamente político. Ello ha situado objetivamente al Tribunal Constitucional en el centro de la controversia política. Desde el momento en que está en juego la vigencia de la Constitución y sus valores y principios en Cataluña, cuando tales actuaciones políticas adoptan formas y tienen efectos jurídicos, los legitimados para impugnarlas es obvio que deben hacer uso de sus atribuciones para defender la Constitución y lo que esta representa. Por otra parte, los tribunales constitucionales o equivalentes no han quedado al margen de conflictos secesionistas planteados en otros Estados y su intervención a veces ha sido crucial a la hora de afrontarlos ${ }^{5}$. Al destacar ese recurso al Tribunal no se quiere defender la idea de que, por tratarse de un conflicto político, el Tribunal debía haberse mantenido ausente de la crisis catalana, es solo la constatación de lo que ha sucedido y de la relevancia política que se ha querido dar a este tipo de respuesta sobre otras más directamente políticas.

Al mismo tiempo que se han producido las impugnaciones ante el Tribunal, y sobre todo, a medida que se ha ido percibiendo que la crisis continuaba y se aceleraba, las Cortes y el gobierno del Estado se han visto obligados a recurrir a instrumentos políticos de orden muy diverso para afrontar la situación, si bien ha primado, sobre todo hasta la celebración del proceso participativo del 9-N

4 El Gobierno está haciendo un uso creciente de la vía judicial. Así, ha impugnado o anunciado la impugnación de otras normas relacionadas con el proceso secesionista, pero están pendientes de resolución. Es el caso del conflicto positivo de competencias contra el Decreto $16 / 2015$, por el que se crea el Comisionado para la Transición Nacional (junio 2015), suspendido por el Tribunal, o los recursos de inconstitucionalidad contra los artículos 69 y 95 y cinco disposiciones adicionales de la Ley 3/2015, de medidas fiscales y financieras (el Tribunal acordó levantar la suspensión del art. 95 y mantener la de los restantes, Auto de 3 de noviembre de 2015), así como del último inciso del artículo 34 de la Ley 2/2015, de presupuestos para 2015 (el Tribunal mantiene la suspensión, Auto de 3 de noviembre 2015), en relación con lo que se conoce como la creación de estructuras de Estado. Se ha anunciado también la presentación de otro conflicto de competencias contra el Decreto 2/2016, de 13 de enero, en lo relativo a la creación de la Consejería de Asuntos Exteriores (29 de enero de 2016), al tiempo que el Gobierno reclama al Tribunal, a través de un incidente de ejecución de la sentencia 259/2015, la nulidad de la Comisión de estudio del Proceso Constituyente, creada por el Pleno del Parlamento de Cataluña el 20 de enero de 2016.

5 Recuérdese la sentencia del Tribunal Supremo de Estados Unidos White vs. Texas de 1869, o ya a finales del s. XX el Dictamen de la Corte Suprema de Canadá de 20 de agosto de 1998 sobre la secesión unilateral de Quebec (Reference Re Secession of Quebec (1998), 2 SCR 217) o los diversos pronunciamientos del Tribunal Constitucional italiano sobre la autodeterminación del Véneto, el último de los cuales está en la sentencia n. 118 de 2015 .

UNED. Teoría y Realidad Constitucional, núm. 37, 2016, pp. 561-592 
2014, la discreción y el perfil bajo, con la salvedad quizás del Ministerio de Asuntos Exteriores. Así, en una ocasión el Congreso de los diputados (abril de 2014) se pronunció sobre la crisis catalana, rechazando ampliamente la proposición de ley orgánica presentada por el Parlamento catalán para que aquél delegara en éste la competencia sobre la autorización de referendos, de modo que la Generalitat pudiera convocar la consulta ${ }^{6}$. En el último momento, se han impulsado y adoptado reformas legislativas cuyo sentido en última instancia se explica a raíz de la crisis catalana (reforma de la LOTC por Ley orgánica 15/2015, de 16 de octubre, para la ejecución de sentencias del Tribunal Constitucional como garantía del Estado de Derecho) aunque no se limite a ella o no la afronte mediante una legislación especial. En todo caso, es un hecho cierto que no se ha seguido ni la vía de la negociación política y/o de apertura de un proceso de reforma constitucional o legislativa relacionadas con dicha crisis (reforma del sistema de financiación por ejemplo, que tocaba en 2015), ni tampoco de rechazo, asimismo político, al plan independentista con la adopción de medidas que supusieran la limitación del ejercicio de la autonomía (así, no se ha puesto en marcha la vía del art. 155 CE a pesar de peticiones en tal sentido). Dejamos de lado la instancia del Gobierno al Ministerio fiscal para querellarse ante el Tribunal Superior de Justicia de Cataluña contra algunos responsables del gobierno catalán (el presidente y dos consejeros) por desobediencia, malversación entre otros delitos, tras la celebración del «proceso de participación ciudadana» del 9-N de 2014, por el apoyo brindado al mismo.

En los apartados siguientes se hará un repaso a las actuaciones normativas y ejecutivas emprendidas por la Generalitat en relación con el proceso secesionista y las impugnaciones de que han sido objeto ante el Tribunal Constitucional por parte del gobierno central, y sobre todo se analizará la respuesta del Tribunal Constitucional a las mismas, ya sea respecto al derecho a decidir y la independencia, ya acerca de los diferentes intentos de llevar a cabo una consulta popular, como instrumento utilizado para ejercer el denominado derecho a decidir la secesión. Antes, a modo introductorio, habrá que hacer unas breves consideraciones sobre la conflictividad constitucional habida antes del inicio de dicho proceso secesionista entre las instituciones catalanas y las estatales, en la que la sentencia del Estatuto (31/2010) marca un hito fundamental para comprender qué ha sucedido en estos últimos años, y también nos referiremos a los precedentes que

6 El Parlamento catalán presentó al Congreso en enero de 2014 una proposición de ley orgánica de delegación en la Generalitat de Cataluña de la competencia para autorizar, convocar y celebrar un referéndum sobre el futuro político de Cataluña. Se pretendía la delegación para la realización de un referéndum de tipo consultivo. En dicha proposición de ley no se menciona para nada la independencia y se subraya su carácter acordado con el Estado. Ver Boletín Oficial de las Cortes Generales. Congreso de los Diputados, X Legislatura, Serie B, n. ${ }^{\circ}$ 158-1, 24 de enero de 2014. El 8 de abril de 2014 el Congreso la rechazó por una mayoría amplia de 299 frente a 47 votos afirmativos y 1 abstención. El debate se puede seguir en Cortes Generales. Diario de Sesiones del Congreso de los Diputados. X Legislatura, n. ${ }^{\circ}$ 192, 2014, 8 de abril 2014. De los diputados catalanes en el Congreso, 26 votaron en contra (PSC y PP) y 22 a favor (CiU, ICV y ERC). 
llegaron al Tribunal Constitucional respecto de situaciones relacionadas con intentos de abordar el derecho a decidir o la autodeterminación, que tuvieron al País Vasco como protagonista.

\section{CATALUÑA Y EL TRIBUNAL CONSTITUCIONAL ANTES DEL INICIO DEL PROCESO SECESIONISTA}

Una lectura somera de las memorias anuales del Tribunal Constitucional pone de manifiesto que Cataluña ha sido la comunidad autónoma que más ha recurrido ante el Tribunal Constitucional en defensa de su autonomía (frente al Estado), constitucional y estatutariamente garantizadas, y cuyas normas, aprobadas por sus instituciones de gobierno y legislativa, han merecido más impugnaciones por parte del gobierno central ante dicho Tribunal. No es el momento de repasar dicha conflictividad competencial, basada sobre todo en un diferente entendimiento de las bases estatales así como de las competencias horizontales del Estado, lo que forma parte de lo habitual — más o menos frecuente- en las controversias constitucionales relacionadas con la división vertical del poder entre Estado y territorios autónomos en Derecho comparado. En todo caso nos parece apropiado reconocer que tal conflictividad ha contribuido, con todo, no solo a un ensanchamiento notable de la autonomía catalana sino, en general, al desarrollo del Estado autonómico como Estado políticamente compuesto ${ }^{7}$.

Basta recordar ahora dos casos singularmente relevantes en la historia de los pronunciamientos del Alto Tribunal con algún tipo de incidencia sobre la autonomía catalana: la impugnación de la Ley Orgánica de Armonización del Proceso Autonómico (LOAPA) de 1982 por parte del Parlamento y del Consejo de gobierno catalanes (entre otros) y los recursos de inconstitucionalidad contra el Estatuto de autonomía de Cataluña de 2006, singularmente el interpuesto por los diputados del Partido Popular, en aquel momento en la oposición. Si la sentencia al recurso previo de inconstitucionalidad contra la LOAPA supuso parar una interpretación reduccionista de la autonomía de nacionalidades y regiones (STC 76/1983), con lo que se afianzó la dimensión política de la autonomía, la sentencia contra el Estatuto catalán laminó las opciones fundamentales del Estatuto - aunque formalmente solo 13 de sus preceptos fueron declarados inconstitucionales-, y abrió una brecha profunda entre el Tribunal Constitucional y las instituciones catalanas, lo que acarreó una deslegitimación política y jurídica del Tribunal entre sectores considerables de la opinión pú-

7 No se entra aquí a discutir las razones — tanto estructurales como políticas - de la conflictividad ni a reiterar el papel del Tribunal Constitucional en la consolidación del Estado autonómico, puesto esto último de relieve muy pronto por M. AraGon, en «Estado jurisdiccional autonómico?», RVAP, n. ${ }^{\circ}$ 16, 1986, pp. 7-12

UNED. Teoría y Realidad Constitucional, núm. 37, 2016, pp. 561-592 
blica catalana. Según una opinión muy común en ámbitos nacionalistas, dicha sentencia estaría en el origen de la escalada secesionista o tendría una relevancia capital en su manifestación ${ }^{8}$.

Sin negar la relevancia que pudo tener la sentencia 31/2010 en el surgimiento del proceso secesionista, no se puede obviar que este había comenzado antes de la emisión de la sentencia. En efecto, el 13 de septiembre de 2009 se inauguran en Arenys de Munt las consultas sobre la independencia, organizadas en muchos municipios catalanes con la cobertura de sus respectivos ayuntamientos. Además de atacarse las nada ejemplares circunstancias relacionadas con la tramitación del recurso - recusación de magistrados, demora de cuatro años en la resolución, un Tribunal partido en dos mitades prácticamente-, se cuestionaba la propia legitimación del Tribunal para enjuiciar una norma que, se decía, era fruto del pacto político, ya que había sido aprobada por dos Parlamentos, el catalán y las Cortes, además de ser ratificada por el cuerpo electoral en referéndum ${ }^{9}$. En el fondo, incluso se reabría el debate - apenas presente en España desde que, al inicio del régimen constitucional, el profesor García de Enterría lo dejara clarificado- sobre la supuesta incompatibilidad entre la democracia y la justicia constitucional.

En cualquier caso, parece evidente que la STC 31/2010 supone un punto de inflexión en el tipo de conflictividad entre Cataluña y el Estado y abre la puerta a la conflictividad ulterior que, además de mantener el enfrentamiento acerca de la distribución de competencias con el Estado central ${ }^{10}$, sobre todo ha tenido como aspecto novedoso y más destacable el tener que hacer frente a impugnaciones derivadas del proceso secesionista. $\mathrm{Y}$ en estos casos, aunque a veces se ha tratado de argumentar en términos de conflictos ordinarios (por parte de los abogados de la Generalitat), el Tribunal no ha podido evitar recurrir a razonamientos específicos para una situación tan particular como es la planteada, como se verá en el apartado IV.

8 En el preámbulo de la Resolución 5/X del Parlament, por la que se aprueba la Declaración de soberanía y del derecho a decidir del pueblo de Cataluña se puede leer «Les dificultats i negatives per part de les institucions de l'Estat espanyol, entre les quals cal destacar la Sentencia del Tribunal Constitucional 31/2010, comporten un refús radical de l'evolució democràtica de les voluntats col.lectives del poble català dins de l'Estat espanyol i creen les bases per a una involució en l'autogovern, que avui s'expressa amb total claredat en els aspects polítics, competencials, financers, socials, culturals i lingüístics».

9 Ver Perez Royo, J., «La STC 31/2010 y la jurisprudencia constitucional a la configuración de un Estado compuesto en España: elementos de continuidad y ruptura, e incidencia en las perspectivas de evolución del Estado autonómico», RCDP, n. ${ }^{\circ} 43,2011$, pp. 121-149.

10 Las últimas memorias del Tribunal Constitucional ponen de manifiesto la elevada conflictividad competencial producida en los últimos años. Así, en la de 2014 (la última publicada) se ve que, de los 16 recursos de inconstitucionalidad interpuestos por el Presidente del gobierno contra leyes de las CCAA, 5 se dirigieron contra leyes del Parlamento catalán, y de las 35 leyes del Estado impugnadas por las CCAA, 11 lo fueron por Cataluña. También 3 de los 4 conflictos positivos de competencias fueron interpuestos por el gobierno catalán.

Ver http://www.tribunalconstitucional.es/es/tribunal/memorias/Documents/MEMORIA_TC_2104.pdf (consultada en diciembre 2015) 


\section{EL PROCESO SECESIONISTA ANTE EL TRIBUNAL CONSTITUCIONAL (2012-2016)}

No es este el lugar para llevar a cabo una pormenorizada explicación y reconstrucción del proceso secesionista vivido en Cataluña en el último cuatrienio, que ya hemos intentado en otros lugares ${ }^{11}$. Solo se van a destacar los sucesos más relevantes en relación con el objeto de este trabajo. Esto es, aquellos que tienen que ver con la aprobación de normas o resoluciones, que fueron recurridas ante el Tribunal Constitucional, con la consiguiente suspensión de las mismas. Se prestará igualmente atención a los procedimientos seguidos para su impugnación, y a aspectos de contexto de la actuación del Tribual, dejando para el apartado siguiente el análisis del contenido de las sentencias.

El Tribunal ha debido lidiar hasta ahora con dos tipos de cuestiones en relación con el proceso secesionista. Por una parte, se ha enfrentado a dos resoluciones aprobadas por el Pleno del Parlamento catalán, respectivamente al inicio de la X y la XI legislaturas (la 5/X de 23 de enero de 2013 y la 1/XI de 9 de noviembre 2015, esta última aprobada por el Parlamento constituido tras las elecciones del 27 de septiembre del mismo año). En la primera de ellas se proclama al pueblo de Cataluña como «sujeto político y jurídico soberano» y se afirma su «derecho a decidir», en el contexto de una «Declaración de soberanía y del derecho a decidir del pueblo de Cataluña». En la segunda «Resolución sobre el inicio del proceso político en Cataluña como consecuencia de los resultados electorales del 27 de septiembre de 2015», se declara el «inicio del proceso de creación de un Estado catalán independiente en forma de república», así como la «apertura de un proceso constituyente...para preparar las bases de la futura constitución catalana», y de «un proceso de desconexión democrática del Estado español», que incluye la no supeditación del Parlament — «depositario de la soberanía y expresión del poder constituyente»- a las instituciones estatales y, en particular, al Tribunal Constitucional.

Por otra parte, el Tribunal se ha pronunciado acerca de la constitucionalidad de la ley que preveía la consulta popular (Ley 10/2014, de 26 de septiembre, de consultas populares no referendarias y otras formas de participación ciudadana) así como sobre el decreto de convocatoria de la consulta popular no referendaria sobre el futuro político de Cataluña y sus anexos (Decreto del presidente de la Generalitat 129/2014, de 27 de septiembre) y acerca de las actuaciones de la Generalitat

11 Ver Castellà Andreu, J.M., «La secesión catalana, entre la política y el derecho», Anuario de la Facultad de Derecho de la Universidad de Alcalá, vol. 7, 2014, pp. 227-240; "Secesión y referéndum sobre el 'derecho a decidir' en Cataluña. Una aproximación desde el Derecho constitucional», en Oliver Araujo, J. (ed.), El futuro territorial del Estado Español, Tirant lo Blanch, Valencia, pp. 451-490; «El problemático encaje constitucional del 'derecho a decidir' de Cataluña y sus vías de ejercicio", Percorsi Costituzionali, n. ${ }^{\circ} 3,2014$, pp. 807-831; «The proposal for Catalan Secession and the crisis of the Spanish Autonomous State», Diritto Pubblico Comparato ed Europeo, n. ${ }^{\circ} 2$, 2015, pp. 429-448. 
relativas a la convocatoria del proceso de participación ciudadana que tuvo lugar el 9 de noviembre de 2014, sin apoyo explícito en ninguna norma concreta. El objeto de la convocatoria de la consulta y de la realización del proceso de participación del 9-N consistió en el sometimiento a los catalanes y residentes en Cataluña mayores de 16 años de las mismas dos preguntas que habían pactado los partidos independentistas en diciembre de 2013 (¿quiere que Cataluña sea un Estado? y, en caso afirmativo, ¿quiere que sea un Estado independiente?).

De este modo, el Tribunal ha intervenido en relación con el fondo de lo planteado por el Parlamento catalán — la constitucionalidad de la secesión y el derecho a decidir-, y también con respecto a los instrumentos para ejercer este último derecho: los diferentes tipos de consulta popular ideados ${ }^{12}$. Lo que para el abogado del Estado en los distintos recursos o impugnaciones interpuestos son contravenciones radicales de los principios nucleares del ordenamiento constitucional (soberanía del pueblo español, unidad, además del procedimiento de revisión constitucional), para los letrados de la Generalitat suponen manifestaciones del principio democrático y del derecho de participación en los asuntos públicos. En la base de ambas cuestiones late la forma de entender el alcance del principio democrático y su compatibilidad con el ordenamiento constitucional.

Así pues, el gobierno del Estado o su Presidente han utilizado en los casos que se comentan dos procesos constitucionales: en una ocasión, el recurso de inconstitucionalidad, frente a la Ley 10/2014, de 26 de septiembre, de consultas populares no referendarias y otras formas de participación ciudadana. En las cuatro veces restantes, la impugnación del artículo 161.2 CE de forma autónoma (procedimiento del Título V LOTC, arts. 76 y 77 LOTC) contra las dos resoluciones reseñadas, así como contra el Decreto del presidente de la Generalitat 129/2014, de convocatoria de la consulta popular no referendaria sobre el futuro político de Cataluña, y finalmente contra las actuaciones de la Generalitat relativas a la convocatoria del «proceso de participación ciudadana» del 9-N ${ }^{13}$. Respecto a esta última impugnación, el Tribunal no por el hecho de que no se invoquen normas específicas (se hizo sin base a ninguna en concreto) deja de admitirla a trámite. Se está ante vías de hecho, esto es, un conjunto de actuaciones no

12 Sigue sin haberse resuelto el recurso contra la Ley 4/2010, de consultas populares por vía de referéndum, que fue impugnada por el Presidente del Gobierno. Hay que subrayar el hecho que no se haya utilizado esta vía, una de las propuestas por el Informe n. ${ }^{\circ} 1$ del Consell Assessor per a la Transició Nacional de 2013 («Informe sobre el futur polític de Catalunya»), ya que dicha ley no obvia la necesaria autorización del referéndum autonómico por parte del Estado.

13 En este caso los letrados de la Generalitat alegan que la impugnación con base al Título V de la LOTC incluye cuestiones de orden competencial, sin haberse interpuesto un conflicto positivo de competencias, razón por la cual piden la inadmisión parcial de la misma. En el FJ 2 de la STC 32/2015 el Tribunal justifica su admisión a trámite en la identidad de requisitos procesales de uno y otro proceso, y considera que cuando la impugnación se base solo en motivos competenciales, «se estará, materialmente, ante un conflicto de competencias, incluso aunque se acuda por la vía prevista en el título V LOTC». En la impugnación de las actuaciones materiales de la Generalitat respecto al proceso participativo del 9-N, el abogado del Estado subsidiariamente menciona el conflicto positivo de competencias. 
formalizadas: «las actuaciones impugnadas son básicamente materiales» (STC 138/2015, FJ 2). En todos los casos que se comentan se invocó y obtuvo la suspensión automática por cinco meses prevista ya sea como aspecto determinante e identificador de la vía del artículo 161.2 CE o como incidente ligado al recurso de inconstitucionalidad (art. 30 LOTC). La suspensión tenía un efecto tangible en el recurso y la impugnación de las consultas no referendarias, el cual no era un objetivo menor a la hora de su planteamiento: su paralización efectiva (no lograda en el caso del proceso participativo del 9-N). En cambio, en las resoluciones citadas lo fundamental de la impugnación no era tanto la suspensión como la utilización de la única vía posible para la impugnación de las mismas y para obtener un pronunciamiento del Tribunal sobre el fondo.

Uno de los aspectos más controvertidos ha sido la impugnación de las dos resoluciones impugnadas, dada la naturaleza jurídica de las mismas. Se trata de dos «propuestas de resolución», aprobadas con base a los artículos 164 y 165 del Reglamento del Parlamento catalán. Son, pues, desde un punto de vista formal, actos de «impulso de la acción política y de gobierno» dirigidos al gobierno y a la ciudadanía. Ello planteó una primera discusión de índole procesal en los dos procesos constitucionales: si debían ser admitidas a trámite sendas impugnaciones por tratarse de actos de impulso político, no normativos, y en consecuencia, tener un alcance meramente declarativo de la voluntad política de la institución que las aprueba.

El Tribunal sostiene su justiciabilidad alegando: a) que expresan la voluntad del órgano del que emana; b) el carácter asertivo de las mismas, ya que «recla$\mathrm{ma}[\mathrm{n}]$ el cumplimiento de unas actuaciones concretas y este cumplimiento es susceptible del control parlamentario previsto para las resoluciones aprobadas por el Parlamento»; c) que son actos definitivos y no de trámite, que concluyen el procedimiento correspondiente de este tipo de actos; y d) que producen efectos ad extra que sirven para dar cobertura a otros actos normativos aprobados por las instituciones catalanas (argumentos contenidos en la STC 42/2014, FJ 2, y luego reiterados en la STC 259/2015, FJ 2, sentencias que resuelven las impugnaciones mencionadas). El hecho que dichas resoluciones pongan fin al procedimiento parlamentario correspondiente, que no es el legislativo sino el de un acto de impulso, lo hacen distinto del caso alegado como precedente por los letrados del Parlamento catalán y por cierta doctrina: la decisión del Parlamento vasco de admitir a trámite el proyecto de Estatuto político de Euskadi, presentado por el gobierno vasco en 2004, que fue impugnado por el gobierno del Estado e inadmitido a trámite por el Tribunal (Auto 135/2004). Además, para los letrados del Parlament, de las resoluciones no se derivan los «efectos jurídicos concretos y reales» a los que aludía el Auto invocado. Para el Tribunal, dichas resoluciones tienen «siquiera indiciariamente» capacidad para producir efectos jurídicos (SSTC $42 / 2014$ y $259 / 2015)$.

La base de la admisión a trámite de las dos resoluciones y lo más discutible en términos constitucionales está, no obstante, en la atribución de carácter jurí- 
dico a tales resoluciones. El Tribunal se apoya en la distinción entre lo jurídico y lo vinculante («lo jurídico no se agota en lo vinculante»). En su opinión, estamos resoluciones que producen efectos jurídicos, además de políticos: «se trata, por tanto, de un acto parlamentario que, sin perjuicio de su veste política, tiene también una indudable naturaleza jurídica» (STC 259/2015, FJ 2). Lo anterior merecería un razonamiento más claro en las dos sentencias comentadas, las cuales se limitan a señalar el reconocimiento que efectúan tales resoluciones en favor del gobierno y el Parlamento catalanes de «atribuciones inherentes a la soberanía» ${ }^{14}$.

A nuestro juicio, a la hora de ponderar la admisión a trámite por el Alto Tribunal de las resoluciones impugnadas, no se puede perder de vista un hecho decisivo, original de las mismas: aunque adoptan la forma de «propuestas de resolución» y siguen el procedimiento previsto para la aprobación de las mismas (argumento formal-ista al que se agarran los letrados del Parlament y la doctrina que lo apoya), su contenido, significado y relevancia políticos escapan de los que son propios de dicho tipo de actos parlamentarios y de la función de impulso u orientación política. Baste ver la significación que se les da, no ya por los grupos impulsores, sino por parte de los mismos órganos de gobierno de la Cámara y el relieve que alcanzan en la vida pública. Materialmente implican actos de naturaleza sui generis, que no parecen regulados específicamente ni por el Reglamento del Parlament ni por ningún otro Reglamento parlamentario (los cuales no suelen prever entre sus funciones la de declarar la independencia, atribución de soberanía o «apertura de un proceso constituyente»), y que no se corresponden con la función de impulso de la acción política, sino con una declarativa, de tipo revolucionario. Estamos ante sendas declaraciones de la voluntad del Parlament de llevar a cabo actos de un proceso que habría de culminar en la creación de un Estado propio. El éxito o no de cada resolución depende de la fuerza política real para hacerla efectiva de parte de las autoridades a las que se dirige, no de los efectos propios de la función parlamentaria de impulso. De ahí la pertinencia de su admisión a trámite, en el marco de un procedimiento tan amplio como el utilizado por el gobierno del Estado — la impugnación del art. 161.2 CE— que incluye actos impugnables muy variados («disposiciones y resoluciones»), procedentes de las autoridades e instituciones de la Comunidad Autónoma. Por otra parte, en las sentencias apenas se argumenta (quizás para evitar alusiones que pudieran tildarse de schmittianas o de iusnaturalistas, o simplemente como controversias doctri-

14 Una valoración de la sentencia 42/2014 con crítica a su admisión a trámite en FossAs EsPADALER, E., «Interpretar la política. Comentario a la STC 42/2014, de 25 de marzo, sobre la Declaración de soberanía y el derecho a decidir del pueblo de Cataluña», REDC, n. ${ }^{\circ} 101,2014$, p. 273 y ss. Ver también los comentarios de Álvarez Conde, E., «Una sentencia con luces y sombras» y de Vintró, J., «El Tribunal Constitucional y el derecho a decidir de Cataluña», ambos en el Blog de la Revista Catalana de Dret Públic, 2-4-2014; de Enériz Olaechea, F.J., «Un comentario a la sentencia del Tribunal Constitucional sobre la declaración de soberanía y el derecho a decidir del pueblo de Cataluña», en Revista Aranzadi Doctrina, n. ${ }^{\circ}$ 4. 2014, p. 33 y ss.; y de Ferreres, V., «The Spanish Constitutional Court Confronts Catalonia's 'Right to Decide'», European Constitutional Law Review, vol. 10, issue 3, 2014, p. 571 y ss. 
nales) en términos de las funciones interpretativa, fundamentadora y legitimadora que dichas resoluciones (materialmente constituyentes en la voluntad de sus patrocinadores) puedan tener respecto a normas aprobadas y a actuaciones de las instituciones catalanas.

Todas las sentencias a las impugnaciones y al recurso interpuestos han sido estimatorias de la inconstitucionalidad, al menos parcialmente (SSTC 42/2014, de 25 de marzo, 31 y 32/2015, de 25 de febrero, 138/2015, de 11 de junio, y 259/2015, de 2 de diciembre), se han dictado por unanimidad de los magistrados (dos de los cuales son catalanes, y una de ellas fue propuesta al Senado por el Parlamento catalán con base a lo dispuesto en el art. 16 de la LOTC reformada en 2007, aunque luego fuese elegida por el Congreso) y lo han hecho en plazos breves, la mayoría de ellas — salvo las sentencias 42/2014 y 138/2015 — antes de agotar el plazo de los cinco meses de la suspensión ${ }^{15}$. Es importante subrayar estos dos últimos hechos pues contrastan con lo acaecido con la STC 31/2010. Desde este punto de vista, el actual Tribunal ha tenido especial cuidado en intentar preservar una imagen institucional que había quedado comprometida en la sentencia contra el Estatuto catalán y que había dado pábulo a acusaciones de politización del Tribunal así como al enfrentamiento entre magistrados, lo que ha sido ampliamente utilizado desde el nacionalismo político y jurídico para desacreditar al Tribunal Constitucional.

\section{LAS ARGUMENTACIONES DEL TRIBUNAL CONSTITUCIONAL EN LAS SENTENCIAS SOBRE EL PROCESO SECESIONISTA}

\section{Antecedente: el caso vasco}

La cuestión de la secesión no se ha planteado de forma completamente novedosa a raíz del caso catalán, aunque ciertamente la crudeza e intensidad de la actual situación no tenga parangón, como tampoco el número de pronunciamientos del Tribunal Constitucional. Este ya tuvo ocasión de afrontar ciertas demandas autodeterministas respecto al País Vasco en los noventa. En 1994 (sentencia 76/1994), el Alto Tribunal debe enfrentarse a un recurso de amparo de unos ciu-

15 Efectivamente, la sentencia por la que se resuelve la impugnación de la resolución 5/X de 2013 es de 25 de marzo de 2014, habiendo sido admitida a trámite el 7 de mayo de 2013 (por ATC 156/2013, de 11 de julio, el Tribunal mantuvo la suspensión), y la impugnación contra la resolución 1/XI de 9 de noviembre de 2015 fue presentada y admitida a trámite el 11 de noviembre y la sentencia es de 2 de diciembre del 2015 (lo que supuso hacerlo en un tiempo récord). El recurso de inconstitucionalidad contra la Ley 10/2014, de 26 de septiembre se interpuso el 29 de septiembre y se resolvió el 25 de febrero de 2015, igual que la impugnación del Decreto de convocatoria de 27 de septiembre, y la impugnación de las actuaciones de la Generalitat relativas a la convocatoria para manifestar la opinión sobre el futuro político de Cataluña a través de un proceso participativo fueron impugnadas el 31 de octubre de 2014, admitidas a trámite el 4 de noviembre y la sentencia es de 11 de junio. 
dadanos del País Vasco, promotores de una iniciativa legislativa popular, contra la resolución de la Mesa del Parlamento vasco denegando su admisión. Se trataba de una iniciativa popular que pretendía recabar firmas para que el Parlamento vasco presentara una proposición de ley ante el Congreso que incluyera una propuesta de reforma de la Disposición Adicional I CE, que incorporara el derecho a decidir del pueblo vasco. Posteriormente, el Tribunal tuvo que hacer frente al recurso de inconstitucionalidad contra una ley — de caso único- aprobada por el Parlamento vasco que establecía una consulta popular sobre el derecho a decidir del pueblo vasco (sentencia 103/2008) ${ }^{16}$. A la doctrina contenida en dichas sentencias se deben sumar otras consideraciones efectuadas por el Alto Tribunal en sentencias anteriores o posteriores sobre los límites de la autonomía y de los derechos históricos o con respecto al significado de los términos nación y pueblo cuando se aplican a sujetos distintos del español.

A la luz de esa doctrina consolidada, y vista ahora muy sumariamente, la autodeterminación no forma parte del contenido del autogobierno de las comunidades autónomas porque la autonomía no equivale a la soberanía (ya señalado en la SSTC 4/1981); el planteamiento de la secesión de un territorio pasa por una ineludible reforma constitucional (STC 103/2008), para la que no hay límites sustantivos (recordando, en la sentencia citada lo afirmado claramente en la STC $48 / 2003)^{17}$; los sujetos que ostentan la iniciativa de reforma constitucional son exclusivamente los mencionados en el artículo 87.1 y 2 CE por remisión del artículo 166 y no otros como una fracción del cuerpo electoral; la participación popular — del conjunto de los españoles - está prevista en su caso solo al final del proceso de reforma (STC 76/1994) ${ }^{18}$; los términos «ciudadanos de Cataluña»,

16 Son varios los comentarios a la misma. Destacamos los de CorCuERA, J., «Soberanía y autonomía. Los límites del derecho a decidir», REDC, n. ${ }^{\circ}$ 86, 2009, pp. 303-341; LópEZ BASAGUREN, A., "Sobre referéndum y Comunidades Autónomas. La ley vasca de la «consulta» ante el Tribunal Constitucional (consideraciones con motivo de la STC 103/2008)», REAF, n. ${ }^{\circ}$ 9, 2009, pp. 202-238; y TAJADURA, J., «Referéndum en el País Vasco», Teoría y Realidad Constitucional, n. ${ }^{\circ} 23,2009$, pp. 363-385.

17 Para el Tribunal, el contenido de la consulta afectaba al régimen constitucional, por lo que no correspondía su resolución a un poder constituido, el autonómico pero tampoco al estatal, sino que debía seguirse el procedimiento de reforma constitucional. Dicha reforma, que no tiene límites materiales y debe llevarse a cabo mediante «el respeto a esos procedimientos [que] es, siempre y en todo caso inexcusable. Es más, tratar de sortear, eludir o simplemente prescindir de esos procedimientos sería intentar una inaceptable vía de hecho (...) para reformar la Constitución al margen de ella o conseguir su ineficacia práctica.» (FJ 4), lo cual vulneraría los principios del artículo 1.1 CE (Estado social y democrático de Derecho). Según la sentencia, la consulta supone «la apertura de un procedimiento de reconsideración del orden constituido que habría de concluir, eventualmente, en «una nueva relación» entre el Estado y la Comunidad Autónoma del País Vasco».

18 «La proposición de ley presentada por los recurrentes no podía prosperar ya que se refería a una materia, la reforma de la Constitución Española, excluida de la iniciativa popular por el artículo 166 C.E. La prohibición consagrada en este artículo implica, sin necesidad de que venga reiterada en otros preceptos, que en esta materia no cabe ejercer la iniciativa legislativa popular en modo alguno — tampoco indirectamente-; es decir, supone vetar la posibilidad de instar, por medio de una iniciativa legislativa popular, el ejercicio de las facultades de iniciativa que en aquel ámbito se reconocen, en lo que aquí interesa, al Parlamento Vasco. La Constitución ha querido reservar la iniciativa legislativa de reforma constitucional al Gobierno, al Congreso de los Diputados, al Senado y a las Asambleas Legislativas de las Comunidades Autónomas, primando los 
«pueblo catalán»o «nación catalana» - a los que alude el Estatuto de 2006 de una manera u otra - no son parangonables con sus homónimos referidos al pueblo o la nación española, de carácter soberano (STC 103/2008 y 31/2010, FFJJ 9 y 11$)^{19}$; y toda consulta popular con apelación al cuerpo electoral mediante el voto supone un verdadero referéndum, por lo que está sujeto al cumplimiento de determinados requisitos sobre quienes deben ser convocados, el procedimiento a observar y las garantías a respetar, y requiere la autorización del gobierno del Estado, sin que pierda la condición de referéndum por el hecho de ser consultivo (STC 103/2008).

Una conclusión a que se llega al analizar la doctrina del Tribunal Constitucional hasta 2014 es que, estando previsto en la Constitución un procedimiento de reforma constitucional, que incluye las mayorías requeridas en cada cámara, la necesidad o no de referéndum según el caso, y los sujetos — tasados- que están legitimados para proponer dicha reforma, no cabe añadir otros requisitos previos, praeter constitutionem, ya sea una iniciativa legislativa popular, ya un referéndum consultivo. Aunque no la menciona expresamente, dicha doctrina guarda un parecido notable con la respuesta a las pretensiones referendarias vénetas dada por la Corte Constitucional italiana. En efecto, hay un paralelismo sustancial entre lo afirmado en la STC 76/1994 y lo señalado dos años antes por la Corte Constitucional en la sentencia n. 470 de 1992 sobre el referéndum consultivo del Véneto. Se rechaza la presión que los proponentes - una fracción del cuerpo electoral con su firma - pudieran ejercer sobre las instituciones representativas llamadas a discutir y aprobar la reforma constitucional. El libre mandato parlamentario se erige como barrera insalvable a este tipo de iniciativas, aunque en el caso español este argumento no aparezca explícitamente a la hora de identificar los motivos del rechazo. También en STC 103/2008, el Alto Tribunal alude a la participación del pueblo español considerado en su conjunto en la reforma constitucional a través del referéndum de ratificación preceptivo (art. $168 \mathrm{CE}$ ), como ocurre asimismo en la sentencia de la Corte italiana n. 496 de 2000.

La relevancia de los pronunciamientos del Alto Tribunal en los casos citados estriba en que sirven de base y fueron en buena medida retomados para resolver las impugnaciones sobre el proceso secesionista catalán. Aunque en lo fundamental las sentencias sobre el caso catalán son tributarias de la doctrina anteriormen-

mecanismos de democracia representativa sobre los de participación directa. Si la Constitución ha prohibido expresamente que la reforma constitucional pueda incoarse como consecuencia del ejercicio de una iniciativa popular, es evidente que servirse de ésta para provocar el ejercicio de una iniciativa parlamentaria, ésta sí legitimada por aquel precepto para iniciar el proceso de reforma, supone contravenir la finalidad perseguida por el constituyente al prever la referida exclusión.» (FJ 5).

19 El Tribunal en la STC 103/2008 ya afirmaba que «la Ley recurrida presupone la existencia de un sujeto, el «pueblo vasco», titular de un «derecho a decidir» susceptible de ser «ejercitado» (...) equivalente al titular de la soberanía, el pueblo español, y capaz de negociar con el Estado constituido por la Nación española los términos de una nueva relación entre éste y una de las Comunidades Autónomas en las que se organiza». 
te citada, aportan algunas novedades destacables, sobre todo en la sentencia 42/2014, como se verá a continuación.

\section{El rechazo de las proclamaciones soberanistas y la constitucionalidad del «derecho a decidir» como aspiración política}

Las sentencias 42/2014 y 259/2015 abordan la legitimidad constitucional de las dos resoluciones mencionadas, que expresan la voluntad del Parlamento catalán en relación con el proceso secesionista.

La sentencia 42/2014 (ponente Adela Asua) separa —a mi juicio, de forma un tanto artificiosa - dos contenidos de la resolución para llegar a dos conclusiones distintas sobre su constitucionalidad.

En primer lugar, declara inconstitucional la mención al pueblo de Cataluña como «sujeto político y jurídico soberano», contenida en el punto primero de la resolución $5 / \mathrm{X}$, por atentar sobre todo contra los artículos 1.2 y $2 \mathrm{CE}$, esto es, los principios de soberanía popular y de unidad. Se recuerda la doctrina de la sentencia 103/2008, según la cual el pueblo de una comunidad autónoma «no es titular de un poder soberano, exclusivo de la Nación [española] constituida en Estado». En efecto, «a ninguna fracción de ese pueblo puede un poder público atribuirle la cualidad de soberano», pues ello supondría «conferir al sujeto parcial del que se predica dicha cualidad el poder de quebrar, por su propia voluntad, lo que la Constitución declara como su propio fundamento». La conclusión de lo anterior es que «una Comunidad Autónoma no puede unilateralmente convocar un referéndum de autodeterminación para decidir sobre su integración en España» (FJ 3). En este punto, el Tribunal cita, como apoyo, de forma genérica, la conclusión «del mismo tenor» del Dictamen del Tribunal Supremo de Canadá. Sin embargo, como ha advertido Fossas, en Canadá se rechaza la secesión unilateral de una provincia, pero no el referéndum unilateral, que cabe en su ordenamiento ${ }^{20}$. Con cita en la STC 31/2010, el Tribunal recuerda que Cataluña es una nacionalidad constituida en Comunidad Autónoma, de acuerdo con la Constitución.

En segundo lugar, el Tribunal lleva a cabo una interpretación conforme de la parte de la resolución relativa al «derecho a decidir» de los ciudadanos de Cataluña (la sentencia siempre utiliza las comillas para aludir al mismo). Al hacerlo, aplica el principio de conservación de los actos de los poderes públicos (y no solo de las normas), ligándolo a la presunción de constitucionalidad de los mismos (FJ 3). En este punto, la sentencia incorpora una modulación significativa en relación con la doctrina constitucional precedente respecto al derecho a decidir. Así, se indica: «El planteamiento de concepciones que pretendan mo-

20 Fossas Espadaler, E., «Interpretar la política. Comentario a la STC 42/2014, de 25 de marzo, sobre la Declaración de soberanía y el derecho a decidir del pueblo de Cataluña», cit., p. 288. 
dificar el fundamento mismo del orden constitucional tiene cabida en nuestro ordenamiento, siempre que no se prepare o defienda a través de una actividad que vulnere los principios democráticos, los derechos fundamentales o el resto de los mandatos constitucionales, y el intento de su consecución efectiva se realice en el marco de los procedimientos de reforma de la Constitución, pues el respeto a esos procedimientos es, siempre y en todo caso, inexcusable.» (FJ 4, cursiva añadida $^{21}$ ). Sentada la indefectibilidad de la reforma constitucional, el párrafo reproducido suscita la cuestión acerca del significado de la distinción entre actividades preparatorias o de defensa de concepciones que pretendan modificar el fundamento del orden constitucional y su consecución efectiva a través de la reforma constitucional.

A la luz de ello, se ha planteado a qué tipo de actos preparatorios estaría aludiendo la sentencia y si es posible admitir algún tipo de consulta o referéndum con anterioridad a la puesta en marcha del procedimiento de reforma constitucional stricto sensu por medio de la iniciativa de reforma. El Tribunal no lo aclara, solo descarta expresamente un referéndum de autodeterminación propiamente dicho. Por ello mismo, en una primera aproximación, podría parecer que no excluye de plano otro tipo de consulta, pero sn precisar de qué tipo. Lo que sí hace es fijar los límites de tales actos preparatorios - y de la consulta en su caso-: el respeto a los principios democráticos, los derechos fundamentales o el resto de mandatos constitucionales.

Así pues, la sentencia reconoce respecto al llamado «derecho a decidir», de entrada, la legitimidad del planteamiento político del mismo, en tanto que «aspiración política», no como derecho propiamente dicho. A esta aspiración solo se puede llegar mediante «un proceso ajustado a la legalidad constitucional con respeto a los principios de 'legitimidad democrática', 'pluralismo' y 'legalidad'». Esto es, el Tribunal cita los mismos principios que aparecen proclamados en la Declaración impugnada. La sentencia 42/2014 es clara al respecto: en sistemas que no son de democracia militante - como el español— cabe que partidos, ciudadanos e instituciones como un parlamento - y esto último también es nuevo pues antes se había dicho de partidos y de cargos públicos representativos- sostengan tal derecho y propongan la modificación de la Constitución para incluir el derecho de decidir en la misma. Ello es así porque «la primacía de la Constitución no debe confundirse con una exigencia de adhesión positiva a la norma fundamental, porque en nuestro ordenamiento constitucional no tiene cabida un modelo de 'democracia militante' (...)» (FJ 4).

Segundo, se identifica la vía jurídica adecuada para su ejercicio: la reforma constitucional. En este caso estaríamos ante una reforma total o sustantiva de la Constitución. El Tribunal Constitucional ha entendido reiteradamente que no

21 La relevancia de este párrafo se pone de manifiesto en el hecho que se reproducirá en todas las sentencias ulteriores que se comentan en este trabajo, salvo en la 32/2015. 
existen límites materiales a la reforma constitucional. No existen límites explícitos en el texto constitucional, tampoco existirían límites implícitos o inmanentes. Esto choca con posiciones autorizadas de un sector doctrinal para el que no sería posible una reforma que atentase contra principios fundantes como el de soberanía del pueblo español y el de unidad de los artículos 1.2 y $2 \mathrm{CE}^{22}$.

Por último, el Parlamento de Cataluña, como el Parlamento de cualquiera de las diecisiete comunidades autónomas, ostenta la iniciativa de reforma constitucional. Por tanto, en sus manos está poner en marcha tal reforma cuando lo considere oportuno (lo que hasta ahora no ha hecho el Parlament ${ }^{23}$ ). Ejercida la iniciativa, corresponderá a las Cortes Generales su discusión y aprobación, a través del procedimiento del artículo $168 \mathrm{CE}$ en el que el pueblo - español- se pronuncia en dos momentos y de dos maneras distintas sobre la reforma: a través del voto en unas elecciones generales entre la aprobación del principio de la reforma y del texto definitivo de la misma por las siguientes Cortes, y en un referéndum de ratificación al final del proceso. La sentencia 42/2014 ha añadido una obligación al Congreso, que deriva del deber de lealtad constitucional: «si la Asamblea Legislativa de una Comunidad Autónoma (...) formulase una propuesta en tal sentido, el Parlamento español deberá entrar a considerarla.» (FJ 4). Esto es, no podría rechazarse de plano la proposición de reforma en el debate de toma en consideración, sino que debería entrar a discutirse su contenido en la Cámara.

A mi juicio, la sentencia, al optar por no rechazar de plano el «derecho a decidir», como había defendido el abogado del Estado, abre una puerta a algún tipo de utilización de instrumentos participativos o de consulta, si bien, acota el campo de actuación de tal «derecho», al no identificarlo con el derecho de autodeterminación y oponerse a la legalidad de un referéndum unilateral sobre la secesión, por tanto a que entrañe capacidad decisoria. También queda acotado al exigir la sentencia el cumplimiento de principios, derechos y preceptos constitucionales. Esto último lleva a transitar un camino más largo y oblicuo en el razonamiento sobre la adecuación constitucional de las vías que pueden hacer efectiva la aspiración o propuesta política sobre el cambio de status jurídico de Cataluña,

22 Así De Vega, P. en La reforma constitucional y la problemática del poder constituyente, Tecnos, Madrid 1985. Aplicado al caso catalán, ver Ruipérez Alamillo, J., «La nueva reivindicación de la secesión de Cataluña en el contexto normativo de la Constitución española de 1978 y el Tratado de Lisboa», Teoría y Realidad Constitucional, núm. 31, 2013, p. 89 ss. En contra Aragón, M., Constitución y Democracia, Tecnos, Madrid, 1989.

23 Ello a pesar de ser una de las cinco vías propuestas por el primer informe del Consell Assessor per a la Transició Nacional. El miedo a repetir lo sucedido a Ibarretxe en 2004, cuando el Congreso rechazó la toma en consideración de la propuesta de reforma —entonces — del Estatuto de autonomía, habría actuado como factor disuasorio para seguir esta vía. Al no hacerlo el Parlamento catalán renuncia a ofrecer a las Cortes su propuesta de revisión constitucional y a iniciar un debate sobre la misma. Se pide diálogo y negociación al Estado pero no se acude al órgano de representación de la soberanía nacional para llevarlos a cabo. Ello pone de manifiesto que el objetivo deseado es la secesión sin más, con la aceptación por las Cortes del hecho consumado o pretendido, no la reforma constitucional. La negociación pretendida sería sobre el cómo de la secesión, no sobre la misma o el qué. 
porque obliga a valorar si cada vía propuesta para ello hasta ahora (u otras que puedan formularse) son conformes o no con la Constitución, pero al final se llega a una conclusión parecida a la que se hubiera obtenido de rechazar de plano el «derecho a decidir», con algún matiz no desdeñable (la no posible inadmisión de plano de la propuesta por el Congreso, como se ha dicho, o la admisión de ciertos actos preparatorios, sin que haya identificado cuáles). Si se toman como referencia las vías propugnadas por el Consell Assessor per a la Transició Nacional y por el Institut d'Estudis Autonòmics, buena parte de ellos nos parecen de muy difícil sino imposible encaje con la Constitución ${ }^{24}$, dejando a salvo —obviamente- la reforma constitucional y, forzando la interpretación, el referéndum del artículo $92 \mathrm{CE}^{25}$. Sobre ello se volverá al final de este subapartado.

La sentencia 259/2015 (ponente Andrés Ollero) reproduce — dos veces- el fragmento que se acaba de comentar, pero el acto o resolución que está en la base de la misma, el contexto político en que se produce, así como el tono, los razonamientos y el fallo de la sentencia son distintos. En efecto, la nueva resolución (la 1/XI de 2015) ya no alude al derecho a decidir y se centra en la apertura de un proceso constituyente «no subordinado» (sic). Ello lleva al Tribunal a rechazar de plano la constitucionalidad de toda la resolución (la cual «muestra una indiscutible unidad de sentido», FJ 3). En la medida en que la resolución atribuye al Parlamento catalán el carácter de «depositario de la soberanía» y «expresión del poder constituyente» (apartado sexto), considera el Tribunal que la misma rechaza la posibilidad de llevar a cabo el objetivo político pretendido a través de una reforma constitucional y opta ya en exclusiva por la vía secesionista unilateral de forma indisimulada. La inconstitucionalidad se extiende asimismo al anexo, en el cual figura la revisión de determinadas leyes, no por el concreto sentido de lo estipulado en ellas sino porque las «'medidas' encomendadas al 'futuro gobierno' lo son desde una resuelta posición de ajenidad al ordenamiento constitucional» (FJ 3).

Ello en línea con lo indicado en la demanda, que considera que la resolución no solo infringe los artículos 1, 2, 9.1 CE y los principios de lealtad constitucional y fidelidad a la Constitución, sino que en realidad supone una ruptura unilateral del orden constitucional. Para el Tribunal, la resolución supone «el acto fundacional» del "proceso de creación de un estado catalán independiente en forma de república» (apartado segundo), y se sirve «de un lenguaje... que se pretende asimismo materialmente 'constitucional'». Con ello entra en colisión con lo establecido en la Constitución de 1978, y con referencia a la

24 En contra, ver Ridao MarTin, J., «La juridificación del derecho a decidir en España», RDP, núm. 91, 2014, p. 110 ss.

25 Ver De Carreras, F., «jUn referéndum?», La Vanguardia, 20 de septiembre 2012; Rubio Llorente, F., «Un referéndum para Cataluña», El País, 8 de octubre 2012; Ruiz Robledo, A., «Una respuesta canadiense a la cuestión catalana», El País, 30 de octubre 2012; Aguado Renedo, C., «Sobre un eventual referéndum consultivo catalán en el proceso soberanista», Cuadernos de Alzate, núm. 46-47, 2013 , p. 27 ss

UNED. Teoría y Realidad Constitucional, núm. 37, 2016, pp. 561-592 
STC 4/1981, subraya: «la unidad del sujeto soberano es fundamento de una Constitución mediante la que la nación misma se constituye, al propio tiempo en Estado social y democrático de Derecho» (FJ 4). Por ello, concluye el Tribunal, la resolución impugnada supone «una infracción constitucional que no es fruto, como suele ocurrir en las contravenciones de la norma fundamental, de un entendimiento equivocado de lo que la misma impone o permite en cada caso. Es resultado, más bien, de un expreso rechazo a la fuerza de obligar de la Constitución misma, frente a la que se contrapone, de modo expreso, un poder que se reclama depositario de una soberanía...Se trata de la afirmación de un poder que se pretende fundante de un nuevo orden político y liberado, por ello mismo, de toda atadura jurídica.» (FJ 6).

Los razonamientos de la sentencia profundizan en dos cuestiones nucleares del constitucionalismo (español y en general del patrimonio constitucional occidental): a) el carácter de norma suprema de la Constitución y el papel reservado al Tribunal Constitucional, y b) la relación entre legitimidad democrática y legalidad y constitucionalidad. Ambos temas latían en el fondo de la resolución impugnada (así como en las manifestaciones políticas - y jurídicas- del soberanismo catalán en estos tiempos: la Constitución entendida como pacto territorial que se habría roto unilateralmente por el Estado al anular el Tribunal Constitucional las opciones de autogobierno contenidas en el Estatuto catalán de 2006, el cual gozaba de un plus de legitimidad democrática respecto a otras normas porque había sido aprobado por el Parlamento catalán, negociado con las Cortes y ratificado en referéndum del pueblo catalán). El Tribunal afronta dichas cuestiones con mayor detenimiento que en la STC 42/2014, donde se limitaba a hacer alguna afirmación concisa al respecto, aunque nada ambigua, por otra parte ( «Todas las manifestaciones del principio democrático tienen su reflejo en el texto constitucional, cuyo ejercicio no cabe fuera del mismo» y «la garantía de la integridad de la Constitución ha de ser vista, a su vez, como preservación del respeto debido a la voluntad popular, en su veste de poder constituyente», FJ 4).

Respecto a la primera cuestión, el Tribunal se reafirma en lo dicho en 2014, con referencia a la STC 76/1988, de que la Constitución no es «resultado de un pacto entre instancias territoriales históricas que conserven unos derechos anteriores» a ella, sino — añade ahora la sentencia — «norma incondicionada y condicionante de cualesquiera otras en nuestro ordenamiento» (FJ 4). Y recuerda, con cita literal de la STC 76/1983, FJ 4, el papel que corresponde al propio Tribunal Constitucional, en tanto que supremo intérprete de la Constitución: «custodiar la permanente distinción ente la objetivación del poder constituyente y la actuación de los poderes constituidos, los cuales nunca podrán rebasar los límites y las competencias establecidas por aquél» (FJ 4).

En relación con la segunda cuestión, para el Tribunal, «en el Estado constitucional, el principio democrático no puede desvincularse de la primacía incondicional de la Constitución». De este modo se liga democracia y constitucionalismo y se rechaza la concepción radical de democracia contrapuesta o al margen del 
Estado de Derecho, como suele hacerse desde posiciones independentistas, las cuales fundan sus pretensiones en la primacía del principio democrático sin más y genéricamente considerado. Este es un argumento sobre el que el Tribunal se detiene extensamente: no existe contraposición entre la reclamada nueva legitimidad democrática catalana y la legalidad y legitimidad de las instituciones del Estado (inclusive la del Tribunal Constitucional) y - ello no es un dato secundario- la misma legitimidad democrática del propio Parlament «que la Constitución reconoce y ampara» (FJ 5).

Para el Tribunal, el principio democrático (al que califica erróneamente como valor superior del ordenamiento) no puede concebirse «como principio constitucional de forma aislada y desvinculada del conjunto del ordenamiento constitucional y sus procesos». La relación entre democracia y primacía de la Constitución, o el entendimiento de esta última como «garantía» de la democracia (y no como su «límite», dirá expresamente), es razonada a partir de tres planos: a) en cuanto a su fuente de legitimación, la Constitución formaliza la voluntad del poder constituyente (el pueblo soberano ratificó el texto constitucional); b) por lo que respecta a su contenido, la Constitución se fundamenta en el respeto a unos valores, entre los que cita la democracia. En cualquier caso, el Tribunal relaciona el principio democrático con el valor (este sí) del pluralismo político, lo que le lleva a afirmar su relación con la unidad de la comunidad política: «Lo que caracteriza a la democracia es la continua toma de decisiones y la apertura a todas aquellas posibilidades que fueron desestimadas en el pasado por cualesquiera razones. Todo ello proporciona capacidad evolutiva al constitucionalismo pluralista propio de nuestro Estado social y democrático de Derecho» (FJ 5). Y como manifestación destacada del pluralismo, cita el pluralismo territorial (y la «dimensión estructuradora de nuestro Estado constitucional que tiene la autonomía constitucionalmente reconocida a las nacionalidades y regiones»); y c) la previsión de los procedimientos de reforma constitucional, la cual «reconoce y encauza la aspiración, plenamente legitima en el marco constitucional, dirigida a conseguir que el poder constituyente constitucionalizado en los artículos 167 y 168 CE revise y modifique la norma fundamental.» (FJ 5).

Sobre este último aspecto, la sentencia resume lo afirmado ya anteriormente por el propio Tribunal, particularmente en la STC 42/2014: que la Constitución no es lex perpetua sino que cabe la revisión total, y que la pueden solicitar las asambleas de las CCAA. En este punto reproduce por dos veces en el mismo fundamento jurídico el fragmento ya referido de dicha sentencia (aunque la primera vez lo cite a partir de la STC 138/2015): la distinción entre actos de preparación y la «inexcusable» consecución efectiva en el marco de los procedimientos de reforma. Sobre la apertura de la norma constitucional y «la libertad para la exposición y defensa públicas de cualesquiera concepciones ideológicas» se agrega ahora, a modo aclaratorio (o aguando el alcance de tal fragmento), «el debate público, dentro o fuera de las instituciones, sobre tales proyectos políticos o sobre cualesquiera otros que propugnaran la reforma constitucional goza, precisamente 
al amparo de la misma Constitución, de una irrestricta libertad. Por el contrario, la conversión de esos proyectos en normas o en otras determinaciones del poder público no es posible sino mediante el procedimiento de reforma constitucional. Otra cosa sería liberar al poder público de toda sujeción a Derecho, con daño irreparable para la libertad de los ciudadanos.» (FJ 7). A lo que añade «cuando, por el contrario, se pretenden alterar aquellos contenidos de manera unilateral y se ignoran de forma deliberada los procedimientos expresamente previstos a tal fin en la Constitución, se abandona la única senda que permite llegar a ese punto, la del Derecho» (cursiva añadida).

Así pues, en opinión del Tribunal la resolución impugnada vulnera el artículo $168 \mathrm{CE}$ porque se sitúa al margen de los procedimientos de reforma. Y con recuerdo de la STC 103/2008, se concluye que eludir o prescindir de dichos procedimientos, los cuales establecen la actuación necesaria de los ciudadanos al final del proceso de reforma, sería «intentar una inaceptable vía de hecho...para reformar la Constitución». En el caso que se comenta, se trata de una vía de hecho para emprender el camino de la secesión, sin molestarse en proponer una revisión constitucional que la previera. Esto es, se pretende transitar la vía de la ruptura constitucional.

A la vista de lo anterior parece que se puede concluir que los actos preparatorios de la reforma constitucional, a los que se alude en las dos sentencias comentadas y en las que se analizarán en el subapartado siguiente, significan, en nuestra opinión, algo más que la — por otro lado obvia - mera cobertura jurídica del debate parlamentario y en la opinión pública (en ejercicio de la libertad de expresión y protegido por la inviolabilidad en el caso de los parlamentarios). Pero, al mismo tiempo, pensamos que tales actos preparatorios no pueden incluir (salvo que se fuerce el sentido del art. $92 \mathrm{CE}$ ) un referéndum previo convocado para una parte del cuerpo electoral (el catalán) que «teste» el apoyo a la opción política que se desea introducir en la reforma y que sirva como espaldarazo al Parlamento catalán, el cual, en uso de sus atribuciones, ponga en marcha la iniciativa de revisión constitucional. Esta contaría entonces con el respaldo o la legitimación política de un hipotético resultado favorable en el referéndum o consulta previa ${ }^{26}$.

Más bien creemos que el Tribunal está admitiendo la posibilidad de plantear un amplio debate público, tanto fuera como dentro de las instituciones, sobre el objeto de la reforma que se pretende o desea. Por tanto, la diferencia entre instituciones de democracia directa o semidirecta y de democracia participativa y deliberativa podría ser útil para distinguir ambos momentos y formas de participación popular: mientras en la fase preliminar a la apertura de la reforma propiamente dicha cabría llevar a cabo formas de democracia participativa entre la ciudadanía catalana (consultas populares no referendarias en el sentido estricto del

26 Así Vintró, J., «La declaració de sobirania i del dret a decidir del poble de Catalunya: un apunt jurídic» [en línea], Blog Revista Catalana de Dret Públic, 7-2-2013. Este entendimiento es el que sostienen los abogados de la Generalitat en el escrito de contestación a la impugnación del Decreto de convocatoria de la consulta del 9-N (Decreto 129/2014), resuelta en la STC 32/2015. 
término y no en el inventado por el legislador catalán siguiendo al Consell Assessor per a la Transició $\mathrm{Nacional}^{27}$ ), solo al final del procedimiento de revisión constitucional el pueblo español en su conjunto tiene la última palabra, y ratifica o no lo acordado por sus representantes en las Cortes ${ }^{28}$.

En definitiva, aunque la STC 259/2015 sigue en lo sustancial a la STC 42/2014, hay diferencias reseñables de tono y énfasis en la argumentación, además de otras ya comentadas. Nos referimos a la defensa contundente de la democracia constitucional frente a otras versiones radicales de la misma, ínsitas en la resolución impugnada. En la sentencia 42/2014 el acento se ponía en el carácter pluralista de la democracia (española) —ausencia de límites a la reforma y rechazo de la democracia militante, apelación al diálogo y la cooperación políticos, distinción entre procedimientos de reforma y actos preparatorios-. Esta representa el momento de máxima apertura por parte del Tribunal, y de cobertura e incitación a un diálogo político entre las instituciones catalanas y las estatales. En la de 2015, sin dejar de lado lo anterior —es más, reiterándolo expresamente-, lo cierto es que ocupa un lugar secundario, pues lo que se remarca ahora es una defensa más articulada de la inseparabilidad entre democracia y constitucionalismo. A la radicalidad de la segunda resolución, aprobada por el Parlament al inicio de la XI Legislatura, el Tribunal Constitucional responde invocando el valor de la democracia constitucional y aclarando a la vez que cerrando la puerta a un entendimiento amplio de los actos preparatorios que incluyan un referéndum. En el siguiente subapartado se volverá sobre ello ${ }^{29}$.

\section{Consultas populares y referéndum}

Hasta ahora nos hemos referido a las sentencias sobre las resoluciones aprobadas por el Parlamento catalán en las que se proclama la voluntad secesionista de la mayoría de los diputados. Vamos ahora a analizar las que han recaído sobre

27 En el próximo subapartado se verá como el Tribunal trata de aclarar cuando se está ante un referéndum y la imposibilidad de soslayar los requisitos y garantías del mismo apelando a una supuesta consulta popular no referendaria o a un proceso participativo, que sustancialmente equivalen al referéndum.

28 Hay un precedente en Derecho comparado que avala esta distinción: la sentencia de la Corte Constitucional italiana n. 365 de 2007 admite que en la reforma del Estatuto de la región especial de Cerdeña de 2006 (rango de ley constitucional) pueda llevarse a cabo una «consulta», como instituto participativo, distinto de los referendos del Véneto rechazados. Sobre ello ver CASTELLÀ, J.M, «Derecho a decidir, secesión y formas de democracia. Un diálogo constitucional entre Italia y España», en CAPpuccio, L. y CorretjA, M. (eds.), El derecho a decidir. Un diálogo ítalo-catalán, IEA, Barcelona, 2013, p. 44.

29 El ya citado Dictamen de la Corte Suprema de Canadá de 1998 alude, aunque no sean tan recordados dichos fragmentos, también a la diferencia entre voluntad soberana y regla de la mayoría «con exclusión de otros valores constitucionales» (par. 67) y a la democracia constitucional: «Entendido correctamente, el constitucionalismo y la primacía del derecho no entran en conflicto con la democracia; antes al contrario, le son indispensables. Sin esta relación, la propia voluntad popular que anima las decisiones democráticas quedaría debilitada.» (par. 78). Se ha utilizado la traducción del Dictamen de C. Chacón y A. Ruíz Robledo, en Cuadernos Constitucionales de la Cátedra Fadrique Furió Ceriol, n. ${ }^{\circ}$ 24, 1998. 
los medios, instrumentos o «vías» —en términos empleados por el Consell Assessor per a la Transició Nacional- que el legislador y el gobierno catalanes han intentado seguir para que el pueblo catalán ejerciera el «derecho a decidir» la secesión: la llamada consulta popular no referendaria (regulada en la Ley 10/2014) y el proceso de participación ciudadana, que es como se denominó a la consulta celebrada el 9-N de $2014^{30}$. Ambas pretendían evitar el referéndum, porque requiere la autorización estatal de su convocatoria (art. 149.1.32 CE). Tanto la consulta como el proceso participativo sometían a la opinión de los electores convocados las mismas dos preguntas, a través de una votación.

Como se ha avanzado ya, el Tribunal Constitucional se ha pronunciado en tres ocasiones sobre la inconstitucionalidad de tales consultas: la Ley de consultas populares no referendarias (STC 31/2015), el decreto de convocatoria de la consulta del 9-N (STC 32/2015) y las actuaciones llevadas a cabo por el gobierno y la administración catalanes en relación con el proceso participativo, que finalmente tuvo lugar, a pesar de la suspensión ordenada por el Tribunal Constitucional (STC 138/2015). A continuación vamos a explicar el contenido más relevante de las mismas, teniendo en cuenta que la doctrina es común a las tres sentencias y se establece sobre todo en la primera de ellas, la sentencia 31/2015 (ponente Pedro González-Trevijano).

El hilo conductor de estos pronunciamientos está en el rechazo de las denominadas consultas populares no referendarias de tipo general (mediante el voto), con el argumento de que se trata sustancialmente de referendos, que no cumplen con los requisitos y las garantías de dicha institución previstos en el ordenamiento español. Esto es, el Tribunal Constitucional aplica la doctrina constitucional del referéndum, establecida sobre todo en la STC 103/2008 y en la STC 31/2010, FJ 69, sobre la constitucionalidad del Estatuto catalán, a dichas consultas, para concluir que se trata de pseudoreferendos o referendos encubiertos, de ahí su inconstitucionalidad. Lo que diverge entre la primera y las sucesivas sentencias es que mientras la 31/2015 trata de la creación legislativa de la figura de la consulta popular no referendaria, las otras dos se refieren a su utilización y a la del proceso participativo respectivamente en relación con el derecho a decidir la secesión.

El fallo de la STC 31/2015 se limita a declarar inconstitucionales las dos primeras frases del artículo 3.3 y los apartados 4 a 9 del artículo 16, además de las dos primeras disposiciones transitorias y de la disposición final primera de la Ley 10/2014, frente al petitum del abogado del Estado, que impugnaba todo el

30 La primera está prevista ya en el Informe n. 1 de dicho Consell y la otra fue ideada sobre la marcha, ante el rechazo de la primera. Se deja de lado en el estudio la otra vía que finalmente se llevó a cabo el 27 de septiembre de 2015: las elecciones llamadas plebiscitarias, pensadas como último recurso en el Informe citado, en caso de fallar las restantes, porque no fueron impugnadas: formalmente se trató de unas elecciones al Parlamento de Cataluña, convocadas por el presidente de la Generalitat de forma anticipada. Otra cosa es la lectura que se quiso dar a las mismas. 
Titulo II (arts. 3 a 39), relativo a las «consultas populares no referendarias», dejando solo a salvo la parte de la ley dedicada a las otras formas de participación ciudadana, que incluye, de forma muy genérica, instrumentos de democracia participativa. De este modo, el Tribunal acota la inconstitucionalidad a las previsiones específicas relativas a las consultas de tipo general — para toda Cataluña o de ámbito local-, y salva las consultas populares no referendarias de tipo sectorial, también reguladas en el mismo Título, así como las disposiciones generales que son de aplicación a unas y a otras consultas, con la aclaración efectuada en el fallo de que estas no son inconstitucionales cuando se apliquen a consultas sectoriales.

El Tribunal comienza recordando su doctrina sobre el «carácter extraordinario» de las formas de participación directa en el ordenamiento constitucional español (contenida especialmente en la STC 119/1995), el cual opta por la democracia representativa - lo cual no viene demasiado al caso en este contexto-, y también la distinción entre las formas de participación directa —entre las que destacan las diversas modalidades de referéndum contempladas en el texto constitucional- que forman parte del contenido del artículo 23.1 CE y son expresiones del derecho fundamental de participación, y otros instrumentos participativos esparcidos a lo largo de la Constitución, además de los que pueda instituir el legislador ordinario, estatal o autonómico, en el marco de sus competencias. En tal caso «se trata de manifestaciones que no son propiamente encuadrables ni en las formas de democracia representativa ni en la democracia directa, incardinándose más bien en un tertium genus que se ha denominado democracia participativa.» (FJ 4).

Esta doctrina general, ya conocida, se pone, a continuación, en relación con las consultas populares, mencionadas en el artículo 149.1.32 CE, que establece la competencia del Estado para autorizar la convocatoria de aquellas que tengan lugar "por vía de referéndum». Por tanto, de ello cabe deducir que hay otras consultas no referendarias, introducidas por el legislador orgánico y estatutario. Es el caso del artículo 122 EAC, que alude a algunas de ellas: audiencias públicas, encuestas, foros de participación. El Tribunal deja claro que ambos tipos de consulta son «dos instituciones de raíz diferente» (FJ 5), tanto teórica como de encaje constitucional, la primera es manifestación del derecho del artículo 23.1 CE, las segundas se conectan con el mandato a los poderes públicos de facilitar la participación, del artículo 9.2 CE. Respecto al referéndum, se reconoce - a diferencia de lo que se decía en la STC 103/2008- que las previsiones constitucionales del mismo «no agota[n] el elenco de referendos admisibles en nuestro ordenamiento». En ese contexto, el Tribunal recuerda su doctrina sobre los rasgos identificadores del referéndum (STC 103/2008 y aplicada en la STC 31/2010, FJ 69): consulta «cuyo objeto se refiere estrictamente al parecer del cuerpo electoral», conformado y exteriorizado a través de un procedimiento electoral (basado en el censo, gestionado por una administración electoral y asegurado con garantías jurisdiccionales específicas), en relación con asuntos públicos, de ahí su vin- 
culación con el derecho fundamental del artículo 23.1 CE, y la necesidad de autorización por parte del Estado. En otro caso, cuando se recaba «la opinión de cualquier colectivo sobre cualesquiera asuntos de interés público, a través de cualesquiera procedimientos» no estaríamos ante un referéndum. Ante esto, se repite una vez más, el tener o no efectos vinculantes no es relevante.

De este modo, el Tribunal fija el parámetro sustantivo que servirá para juzgar la ley recurrida. En primer lugar, la distinción entre cuerpo electoral como destinatario del llamamiento a la ciudadanía (los que tienen reconocido el derecho de sufragio) y colectivos que articulan voluntades particulares o colectivas, pero no generales. En el caso del referéndum se participa en cuanto ciudadano (uti cives), en las otras consultas se hace a título individual o como miembro de un colectivo. En segundo lugar, en el referéndum la opinión del cuerpo electoral se expresa a través del sufragio, emitido en un proceso electoral. De ahí la necesidad de observar procedimientos y garantías, jurídicamente previstos. Son los medios que se orientan a un fin, que es el de «garantizar la realidad y veracidad del juicio emitido por el cuerpo electoral» (FJ 5). En este punto el Tribunal recuerda cómo los derechos se ejercen «en la forma jurídicamente prevista en cada caso», mientras que en las otras consultas se utilizan otras formas de exteriorizar la opinión distintas del voto ${ }^{31}$.

Pero el Tribunal se refiere asimismo a la cuestión de la distribución de competencias en esta materia, el otro aspecto a tener en cuenta a la hora de enjuiciar la ley catalana. En este punto la sentencia incluye - de forma no precisa técnicamente- las reservas de ley orgánica implicadas en el caso. En efecto, el régimen jurídico del referéndum está cubierto por una doble reserva de ley orgánica: la específica del artículo 92.3 CE (que afecta a las «condiciones y procedimientos» de los referendos previstos en la Constitución) y la genérica del artículo $23 \mathrm{CE}$ en relación con lo previsto en el artículo $81 \mathrm{CE}$ para el «desarrollo» de los derechos fundamentales. La Ley orgánica 2/1980, reguladora de las distintas modalidades de referéndum, es la «única ley constitucionalmente adecuada» para el cumplimento de ambas reservas. El Tribunal constata como dicha ley no se refiere a las consultas de ámbito autonómico (excepto las de los arts. 151 y 152 CE) y remite a la legislación básica de régimen local las consultas municipales.

Respecto a las competencias en juego, el Tribunal recuerda el alcance de la competencia estatal del artículo 149.1.32 CE establecido en la sentencia 31/2010, FJ 69, y que ahora se reproduce, en términos que van más allá de los literales del precepto — la autorización de la convocatoria — para incluir «la entera disciplina

31 El Tribunal no considera el criterio del objeto de la consulta, que también habían tenido en cuenta los votos particulares de E. Aja y P. Jover al Dictamen del Consejo de Garantías Estatutarias 19/2014, de 19 de agosto, sobre la constitucionalidad de la proposición de ley, a la hora de distinguir entre el referéndum y las consultas: los referendos consultivos versan sobre cuestiones políticas de especial trascendencia. Este criterio también lo tiene en cuenta MARTIN, E., en «El referéndum y las consultas populares en las comunidades autónomas y municipios», RVAP, n. ${ }^{\circ}$ 94, 2012, p. 95 y ss. 
de esa institución, esto es, [a] su establecimiento y regulación.» Se menciona, en relación con las consultas locales, la competencia sobre las bases del régimen jurídico de las administraciones públicas del artículo 149.1.18 CE, pero no —lo cual sorprende- la competencia estatal del artículo 149.1.1 CE en relación con los derechos fundamentales (se cita más tarde en el FJ 9). En cuanto a las competencias autonómicas, el Tribunal reitera su doctrina sobre la inexistencia de competencias implícitas sobre la materia, y que las competencias deben estar expresamente previstas en normas del Estado, incluidos los Estatutos de autonomía (así se establece en la STC 103/2008, FJ 3, aunque la STC 31/2010, lo acotaba más: concretamente a la ley orgánica de referéndum). Aplicando esta doctrina, que aparece ya en la sentencia del Estatuto catalán, y en ausencia de previsión del referéndum autonómico en la Ley orgánica de referéndum de 1980, el Tribunal Constitucional circunscribe la competencia de la Generalitat (art. 122 EAC) a las consultas no referendarias, ya que el referéndum no es mencionado expresamente y solo se puede deducir de la cláusula residual «cualquier otro instrumento de consulta popular».

Hasta aquí se trata de un recordatorio de cosas ya dichas por el Tribunal. La sentencia 31/2015, FJ 6, aprovecha para recapitular de sentencias previas y resaltar dos límites a dicha competencia reconocida de la Generalitat respecto a las consultas no referendarias (además de la competencia básica del Estado en relación con las consultas locales, ex art. 149.1.18, ya citada): 1) no se pueden formular consultas de ningún tipo «aun no referendarias», «que incidan 'sobre cuestiones fundamentales resueltas con el proceso constituyente y que resultan sustraídas a la decisión de los poderes constituidos...'. Es patente, pues, que el parecer de la ciudadanía sobre tales cuestiones ha de encauzarse a través de los procedimientos constitucionales de reforma.» Se retoma aquí, con cita literal incluida, lo sostenido en la STC 103/2008. Cuando dicha sentencia dice que «no caben actuaciones por otros cauces» distintos de la reforma constitucional, ¿significa que ello incluye también los instrumentos de participación? ${ }^{32}$. Por tanto, de lo apuntado hasta aquí se concluye que, cuando se trate de cuestiones constitucionales, quedarán excluidas no solo las consultas referendarias sino también las no referendarias en el sentido estricto del término, esto es, los instrumentos de democracia participativa, sin apelación al voto del cuerpo electoral. Se trata de una interpretación posible pero no la única admisible de lo dicho por el Tribunal en 2008: entonces todo pivotaba sobre una consulta popular que escondía un referéndum. En la sentencia de 2015 se resalta expresamente la negativa a otros posibles tipos de consulta.

La cuestión entonces es cómo evitar que esta afirmación del Tribunal entre en contradicción con otra del mismo Tribunal, que se pone a continuación. En efecto, al mismo tiempo, este reitera el fragmento de la STC 42/2014, FJ 4, ya

32 También en la STC 31/2010, FJ 69, se dice que a «todo tipo de consultas» rigen los límites materiales del FJ 4 de la sentencia invocada de 2008.

UNED. Teoría y Realidad Constitucional, núm. 37, 2016, pp. 561-592 
comentado, en el que se distingue la reforma propiamente dicha de la realización de actos preparatorios. De entrada parece que la exclusión de toda posible consulta - referendaria y no referendaria en el sentido estricto del término- choca contra este párrafo ahora reproducido, salvo que los actos preparatorios queden referidos solo a manifestaciones encuadrables en la libertad de expresión. La secuencia de lo sostenido por el Tribunal es la siguiente: lo afirmado en 2008 se complementa con lo sostenido en 2014 sobre los actos preparatorios, pero la sentencia 31/2015 cierra el paso a todo tipo de consultas. Por tanto, en una interpretación que trate de integrar ambos razonamientos a priori incoherentes contenidos en la sentencia de 2015, con orígenes en sentencias distintas, como se ha visto, entendemos que no cabría utilizar instrumentos de participación ni consultas referendarias en el procedimiento de la reforma constitucional, pero sí serían admisibles dichos instrumentos como actos preparatorios de la misma, no las consultas a través del voto. Nos remitimos a la interpretación del mismo dada al final del subapartado anterior.

El segundo límite que introduce el Tribunal es que el objeto de las consultas no puede desbordar el ámbito de las competencias autonómicas y locales, tal y como contempla el artículo 122 EAC y recuerda la STC 31/2010.

A la luz de los criterios recordados o fijados en la sentencia, el Tribunal concluye su argumentación analizando si y en qué medida la consulta popular no referendaria participa de la naturaleza del referéndum, como sostiene el Abogado del Estado. Para ello, se parte de un criterio determinante del fallo, que se reiterará en las sentencias ulteriores sobre la materia: «dicho juicio debe verificarse al margen del nomen iuris asignado a las consultas reguladas...Por tanto, ni un referéndum dejará de serlo tan solo porque la norma legal que lo prevea le niegue la condición de tal, ni el derecho ex artículo 23.1 CE a la participación directa en los asuntos públicos perderá su fuerza vinculante porque la ley, de nuevo, niegue haber procedido a su regulación o desarrollo» (FJ 7).

Establecido este criterio general, la sentencia pasa a distinguir los distintos tipos de consulta previstos en la Ley 10/2014, a efectos de determinar su constitucionalidad o no. Y ahí opta por una posición deferente con el legislador catalán: las consultas sectoriales, en función del sujeto jurídico llamado a la consulta, suponen un llamamiento a un sujeto más restringido que el cuerpo electoral sea de la comunidad autónoma, sea local. Por tanto, pueden incluirse dentro de la competencia de la Generalitat del artículo 122 EAC. Por el contrario, respecto a las consultas generales, la sentencia juzga que son aplicables los requisitos del referéndum: a) son llamadas al cuerpo electoral, mediante el sufragio, para manifestar la voluntad general. Para el Tribunal, esta conclusión no se ve empañada por el hecho de que dicho electorado — ciudadanos de Cataluña — se vea «acrecido» por incorporaciones de otras personas, tal y como dispone la ley (menores entre 16-18 años y residentes de otros Estados, los cuales también son convocados, según el Tribunal, ya sea en su condición política de catalanes, los primeros, y de nacionales de terceros Estados, los segundos, no como miembros de colectivos). Dichas 
consultas generales son, pues, una «verdadera apellatio ad populum». Y b) la ley regla un verdadero procedimiento «electoral» con normas sobre la convocatoria, la campaña o las normas de voto. Para la sentencia, «lo relevante, pues, no es que el procedimiento y las garantías no sean idénticos a los previstos en la legislación electoral estatal, sino que comporten un grado de formalización de la opinión de la ciudadanía materialmente electoral» (FJ 8). En definitiva, «la Ley analizada entra a regular con otro nombre los institutos jurídicos que califican a la consulta popular como referendaria.» $\mathrm{Al}$ hacerlo, el legislador catalán ha obviado la aplicación de los preceptos constitucionales que rigen el referéndum.

Al hacer un juicio abstracto sobre una (formalmente) ley general, susceptible de ser aplicada a situaciones variadas, el Tribunal utiliza como criterio de determinación de su inconstitucionalidad el que la consulta no referendaria regulada sea un referéndum encubierto, sin entrar a fondo en la cuestión, porque no es el lugar para hacerlo, de las materias sobre las que versarán las distintas consultas que se convoquen, esto es, si sobre temas ordinarios de competencia autonómica o sobre temas de relevancia constitucional. Esto queda para los actos de aplicación de la ley. Aunque, como se ha visto, aprovecha la ocasión para fijar los límites sustantivos y competenciales de las consultas populares, y enfatizar con carácter general la imposibilidad de cualquier tipo de consulta cuando afecte a asuntos constitucionales, como recordatorio-anticipo de una doctrina a aplicar a supuestos concretos cuando se tercie. Y de hecho se terció bastante pronto.

La sentencia 32/2015 (ponente Juan Antonio Xiol) declara inconstitucional y nulo el Decreto 129/2014, de convocatoria de la consulta popular no referendaria sobre el futuro político de Cataluña y sus anexos, puesto que considera que tiene carácter referendario, tal y como sostenía el abogado del Estado. El Tribunal se limita a aplicar la doctrina de la STC 31/2015 en relación con la identificación de las consultas populares no referendarias con el referéndum al caso, ya que el Decreto convoca una consulta al amparo de dicha Ley y, en desarrollo de la misma, establece la regulación específica que rige la consulta convocada. Dados los sujetos convocados y al hacerlo mediante sufragio, y de acuerdo con lo previsto para la consulta general prevista en la ley declarada inconstitucional en dicho punto, «se está convocando una consulta referendaria». Además, se vulneran las competencias del Estado en materia de referéndum «al haber convocado un referéndum sin la preceptiva autorización estatal...y sin seguir los procedimientos y garantías constitucionalmente exigidos» (FJ 3). En cambio, curiosamente, esta sentencia no entra en la cuestión de los límites, en concreto, el que alude a la naturaleza de orden constitucional del objeto de la consulta, contenido, como se ha visto, en la STC 31/2015.

Por último, la sentencia 138/2015 (ponente Adela Asua) declara inconstitucionales, según reza el fallo, las actuaciones de la Generalitat en relación con la convocatoria del "proceso de participación ciudadana» contenidas en la página web «participa2014.cat» así como los actos y actuaciones preparatorias para la realización de dicha consulta y cualquier otra actuación no formalizada 
jurídicamente vinculada a la referida consulta. Adviértase que no se anula el proceso participativo en sí sino las actuaciones (ya realizadas en el momento de dictarse al sentencia) de la Generalitat. Por tanto, se trata de actuaciones materiales, a diferencia del caso visto en el párrafo anterior. No hay acto formal de convocatoria, ni registro de participantes, ni procedimiento, ni garantías establecidas. Estas son las peculiaridades principales del caso. El Tribunal centra su análisis en si las actuaciones del Gobierno de la Generalitat en el proceso de participación ciudadana se excedían o no de la competencia en consultas no referendarias del artículo $122 \mathrm{EAC}$, en el doble sentido de si es competencia del Estado o de la Generalitat, por una parte, y si afecta a una cuestión constituyente o constituida, por la otra. En este punto, el Tribunal reproduce la parte de la sentencia 31/2015, FJ 6, ya vista, y que contempla dos límites para todas las consultas autonómicas, sean referendarias o no (ceñirse al ámbito de sus competencias y no incidir sobre cuestiones fundamentales resueltas en el proceso constituyente). Por tanto, el Tribunal sostiene que ha de entrar, porque es «determinante», en el contenido de la pregunta sometida a consulta, sin que sea relevante el grado de formalización jurídica de la misma. La sentencia constata como las dos preguntas formuladas en el proceso de participación ciudadana del 9-N inciden sobre cuestiones que corresponden al poder constituyente. La formulación de estas preguntas presupone un reconocimiento indirecto a Cataluña de atribuciones contrarias a la Constitución, ya que parten de identificar a los ciudadanos de Cataluña como pueblo soberano (FJ 4). Y recuerda que tales cuestiones han de encauzarse a través de los procedimientos constitucionales de reforma. En este punto vuelve a incorporar el fragmento de la STC $42 / 2014$, ya citado, donde distingue la reforma constitucional de los actos preparatorios de la misma.

En definitiva, las últimas dos sentencias que se acaban de comentar sostienen la inconstitucionalidad de las consultas sobre el futuro político de Cataluña, aunque difieran de los motivos en que se basan. En primer lugar, el Tribunal se refiere a la afectación de tales consultas a decisiones propias del poder constituyente, que excluyen de plano la intervención de la comunidad autónoma (y del Estado), en tanto que poderes constituidos (STC 138/2015). Segundo, motivos sustantivos: se argumenta que tales consultas son materialmente de naturaleza referendaria, porque suponen una apelación a la ciudadanía mediante el voto y establecen un procedimiento y garantías para ello (en la STC 32/2015). Tercero, un aspecto competencial, en base al cual la competencia sobre referéndum corresponde al Estado a partir de la interpretación amplia del artículo 149.1.32 CE (también en la misma sentencia). Por último, también de orden competencial, se alude a las competencias sobre las consultas populares no referendarias, donde se incluyen los procesos participativos, las cuales no pueden alterar el procedimiento de la revisión constitucional ni ser consideradas como actos preparatorios de la misma, por lo que no pueden tener lugar (STC 138/2015). 
Como se ha visto, la aplicación estricta de los dos límites señalados por el Tribunal Constitucional en la sentencia 31/2015, FJ 6 y aplicados en la STC $138 / 2015$, cerrarían la puerta a toda forma de participación o consulta popular, y ello chocaría con la afirmación de la STC 42/2014, reiterada en las mismas sentencias, que separa los actos preparatorios de la reforma constitucional propiamente dicha. Por tanto, a mi juicio, cabe deducir que solo las verdaderas consultas no referendarias, esto es, las identificadas con las figuras de democracia participativa, podrían ser utilizadas como actos preparatorios de la reforma constitucional. Por el contrario, el Tribunal veta toda posible consulta por vía de referéndum o parangonable al mismo en relación con asuntos propios de la Constitución. Con ello se estaría acotando el sentido del fragmento comentado de la STC $42 / 2014$, sin vaciarlo completamente de contenido, como parecen hacer las últimas sentencias comentadas, pero sí excluyendo el referéndum del artículo $92 \mathrm{CE}$.

\section{A MODO DE CONCLUSIÓN}

Como se ha visto al estudiar tanto los pronunciamientos del Tribunal Constitucional sobre las resoluciones secesionistas aprobadas por el Parlamento catalán al inicio de las dos últimas legislaturas como sobre las normas y actos sobre las consultas no referendarias, la reforma constitucional aparece como la vía insoslayable para afrontar las demandas secesionistas de una parte considerable de la población catalana, a la vez que se rechazan atajos jurídicos bajo la forma de consultas populares. Este es el principal rasgo común de todas las sentencias comentadas. El Tribunal se apoya, como pilares de sus razonamientos, en un entendimiento del principio democrático en la Constitución que responde a las ideas de democracia pluralista (y no militante, admitiendo la posibilidad de una revisión que admita la independencia), constitucional (y no al margen de sus principios, derechos y preceptos) y representativa (con papel marginal de la participación directa).

Aunque formalmente se pueda considerar, como hicieron los abogados de la Generalitat y los académicos que sostienen el derecho a decidir la secesión, que las consultas populares no referendarias no producen los efectos jurídicos y políticos de un referéndum y que solo pretenden recabar la opinión de la ciudadanía en un tema de naturaleza política como lo es el planteado en Cataluña desde 2012, no se puede soslayar la cuestión de fondo expresada en las resoluciones aprobadas por el Parlament de Cataluña, de forma descarada en la segunda —en la que se aboga por una secesión unilateral- (1/XI de 2015), pero igualmente clara en la primera ( $5 / \mathrm{X}$ de 2013) cuando afirma el carácter soberano del pueblo de Cataluña. Estas abocan a una pretensión de ruptura del orden constitucional y de la unidad del Estado, con la aparición de un nuevo poder constituyente, el pueblo catalán, al que las consultas habrían de servir para aflorarlo y legitimarlo en términos políticos y democráticos. En este caso, esta- 
mos ante una manifestación del principio democrático en sentido radical o revolucionario, aunque se quiera servir de instrumentos jurídicos ordinarios (las consultas no referendarias), los cuales tienen ya de por sí, y considerados en abstracto, un encaje muy dudoso en el sistema constitucional, en la medida que presentan rasgos básicos de un referéndum. Es más, son figuras que se crean para soslayar los requisitos y garantías propios de la institución referendaria en el ordenamiento español. Y aunque, con una interpretación amplia de la Constitución, se pueda considerar cada uno de los instrumentos impugnados ante el Tribunal que es conforme a la misma, una interpretación teleológica de todos ellos, vistos sistemáticamente como partes de un plan coherente, no arroja dudas acerca del objetivo perseguido.

El Tribunal se ha visto abocado por medio de estas impugnaciones al centro de la gran controversia política que es el intento secesionista en Cataluña, sobre todo por la práctica ausencia de otro tipo de respuestas, específicamente políticas. Ante el riesgo de aparecer como ariete en manos del gobierno del Estado y de sufrir una deslegitimación institucional (real en ciertos sectores de la opinión pública catalana), el Tribunal ha resuelto en plazos breves y por unanimidad las impugnaciones y recurso planteados (lo que ciertamente no contribuye a la precisión y coherencia doctrinal de las sentencias), evitando así hacer seguidismo del Ejecutivo en sus pretensiones. En este sentido, el Tribunal proclama (en la sentencia 42/2014 — y reproduce en la sentencia 31/2015, FJ 6-) y lleva a la práctica (en ambas sentencias) el self restrain. Así, se dice en la primera sentencia mencionada, que los problemas que tratan en ella los derivados de la voluntad de una parte del Estado de alterar su status jurídico- «no pueden ser resueltos por este Tribunal...por ello los poderes públicos muy especialmente los poderes territoriales que conforman nuestro Estado autonómico son quienes están llamados a resolver mediante el diálogo y la cooperación los problemas que se desenvuelven en este ámbito... A este Tribunal incumbe únicamente, a iniciativa de las partes legitimadas para recabar su intervención, velar porque los procedimientos que se desarrollen en el curso de este diálogo se ajusten a los requisitos exigidos por la Constitución.» (FJ 4). Se trata de un recordatorio, por una parte, a los poderes públicos, concretamente a quienes impugnan, esto es, al gobierno del Estado, de los límites de la justicia constitucional a la hora de afrontar problemas políticos de la índole de los que se están comentando, con un llamamiento a todos los poderes públicos y actores políticos implicados para que se esfuercen en buscar una solución; y por otra, de la función supervisora del propio Tribunal de la adecuación a la Constitución del resultado del diálogo, cuando se acude al mismo. Asimismo, el Tribunal lleva a cabo un ejercicio práctico de autocontención en el momento de declarar inconstitucionales las resoluciones o las normas impugnadas, optando por circunscribir la inconstitucionalidad a aquellas disposiciones o partes de la resolución que son insalvables en términos de adecuación a la Constitución, e interpretando conforme a esta el resto 
de preceptos impugnados, ni que sea al precio de forzar su significado y descontextualizarlo ${ }^{33}$.

Por último, aunque el Tribunal Constitucional suela mostrase, como regla general, muy parco a la hora de utilizar de forma expresa el Derecho comparado en apoyo a sus argumentos, sin embargo, en la sentencia 42/2014 lo hace, trayendo a colación el caso canadiense. Es sabida la relevancia y la reputación del Dictamen de la Corte Suprema de Canadá sobre la secesión unilateral de Quebec tanto en Canadá como en Derecho comparado, y como marca un antes y un después en la doctrina jurisprudencial comparada sobre secesiones de territorios en Estados liberal-democráticos ${ }^{34}$. De ahí que su cita no sea nada casual y responda a un intento de acercamiento a la doctrina canadiense en el rechazo constitucional de una secesión unilateral, al tiempo que reconoce el «derecho a decidir» como aspiración política y distingue la reforma de la Constitución de actos preparatorios de la misma. Pero en general los razonamientos del Tribunal guardan una mayor cercanía, aunque no la haya citado expresamente, con la argumentación llevada a cabo por la Corte Constitucional italiana ${ }^{35}$. Aunque ciertamente dicha Corte no ha asumido el protagonismo en la vida pública italiana que ha tenido el Tribunal Constitucional español a la hora de abordar los casos de secesión planteados, de entrada, porque hasta ahora la gravedad de una situación no es comparable con la otra.

$* * *$

TITLE: Constitutional Court and Catalan secessionist process: constitutional law answers to a constitutional politics conflict

ABSTRACT: The essay deals with the five rulings dictated by the Constitutional Court in 2014-15 in relation with the secessionist process started in Catalonia in 2012. Most of the cases follow the procedure of section 161.2 Spanish Constitution and Title V of the Organic Law of the Constitutional Court. They are focused on i) the constitutionality of two resolutions passed by the Catalan Parliament on the right to decide, the sovereignty of Catalan people and the beginning of the political and constituent processes and ii) the regulation and exercise of the instruments to reach the secessionist process followed until now: a so-called popular consultation without referendum and a participatory process. The rulings take into account the contradiction of the norms and acts contested with the Constitution, in both substantive and allocation of powers perspectives.

33 También desde este punto de vista, hay una relación manifiesta con la posición de self restrain de los jueces de la Corte Suprema de Canadá en el Dictamen aludido de 1998 sobre la secesión de Quebec. Ver pars. 100 y 101.

34 López Basaguren, A., «La secesión de territorios en la Constitución española», Revista de Derecho de la Unión Europea, n. ${ }^{\circ} 25,2013$, p. 90.

35 Por última vez y matizando la anterior doctrina en la sentencia n. 118 de 2015, en relación con la ley regional del Véneto 16 de 2014 en la que se prevé que la Asamblea convoque un referéndum consultivo sobre si el Véneto debe convertirse en una república independiente y soberana. Ver un comentario a la misma en FAso$\mathrm{NE}, \mathrm{C}$., «Una, indivisibile, ma garantista dell'autonomia (diferenziata): la Repubblica italiana in una recente pronuncia della Corte Costituzionale sulle leggi regionali venete nn. 15 e 16 del 2014», Blog de la Revista Catalana de Dret Públic, 15-9-2015.

UNED. Teoría y Realidad Constitucional, núm. 37, 2016, pp. 561-592 
For the Court the constitutional amendment is ineluctable to confront the secessionist process. We conclude that the Constitutional Court assumes in the different rulings differently the obligations of a pluralist and of a constitutional democracy.

Resumen: En este estudio se pasa revista a las cinco sentencias dictadas por el Tribunal Constitucional entre 2014 y 2015 en relación con el proceso secesionista iniciado en Cataluña en 2012. Buena parte de las impugnaciones siguen el procedimiento del artículo 161 CE y Titulo V LOTC y versan unas sobre la constitucionalidad de dos resoluciones aprobadas por el Parlamento de Cataluña en las que se plantea el derecho a decidir, el carácter soberano del pueblo de Cataluña y el inicio del proceso político y de un proceso constituyente, y las otras sobre la regulación y aplicación de los instrumentos para llevar a cabo el proceso secesionista seguido hasta ahora: una llamada consulta popular no referendaria y un proceso de participación ciudadana. Las sentencias advierten contradicciones con la Constitución de las normas y actos impugnados tanto de carácter sustantivo como de orden competencial. Para el Tribunal la reforma constitucional es ineludible a la bora de afrontar el proceso secesionista con respeto al ordenamiento jurídico. Se concluye que el Tribunal en las diferentes sentencias emitidas otorga distinta relevancia a las exigencias de la democracia pluralista y a las de la democracia constitucional.

KEY WORDS: secession, right to decide, consultation, referéndum, constitutional amendment.

PALABRAS Clave: secesión, derecho a decidir, consulta, referéndum, reforma constitucional.

FECHA DE RECEPCIÓN: 15.12.2015 Fecha de aceptación: 16.01.2016 